\title{
Convergence of algorithms for fixed points of generalized asymptotically quasi- $\varphi$-nonexpansive mappings with applications
}

\author{
Xiaolong Qin ${ }^{1}$, Ravi P Agarwal ${ }^{2}$, Sun Young $\mathrm{Cho}^{3^{*}}$ and Shin Min Kang ${ }^{4^{*}}$
}

\author{
* Correspondence: ooly61@yahoo. \\ co.kr; smkang@gnu.ac.kr \\ ${ }^{3}$ Department of Mathematics, \\ Gyeongsang National University, \\ Jinju 660-701, Republic of Korea \\ ${ }^{4}$ Department of Mathematics and \\ RINS, Gyeongsang National \\ University, Jinju 660-701, Republic \\ of Korea \\ Full list of author information is \\ available at the end of the article
}

\begin{abstract}
In this article, strong convergence of Krasnoselski-Mann iterative sequences and Halpern iterative sequences are investigated based on hybrid projection methods. Strong convergence theorems for common fixed points of a family of generalized asymptotically quasi- $\boldsymbol{\varphi}$-nonexpansive mappings are established in the framework of Banach spaces.

Mathematics Subject Classification 2000: 47H09; 47J05; 47J25

Keywords: asymptotically quasi- $\boldsymbol{\varphi}$-nonexpansive mapping, asymptotically nonexpansive mapping, fixed point, generalized asymptotically quasi- $\varphi$-nonexpansive mapping, generalized asymptotically quasi-nonexpansive mapping
\end{abstract}

\section{Introduction}

Fixed point theory as an important branch of nonlinear analysis theory has been applied in the study of nonlinear phenomena. During the four decades, many famous existence theorems of fixed points were established; see, for example, [1-5]. However, from the standpoint of real world applications it is not only to know the existence of fixed points of nonlinear mappings, but also to be able to construct an iterative process to approximate their fixed points. The computation of fixed points is important in the study of many real world problems, including inverse problems; for instance, it is not hard to show that the split feasibility problem and the convex feasibility problem in signal processing and image reconstruction can both be formulated as a problem of finding fixed points of certain operators, respectively (see [6,7] for more details and the references therein).

Recently, the study of the convergence of various iterative processes for solving various nonlinear mathematical models forms the major part of numerical mathematics. Among these iterative processes, Krasnoselski-Mann iterative process and Halpern iterative process are popular and hot. Let $C$ be a nonempty, closed, and convex subset of a underlying space $X$, and $T: C \rightarrow C$ a mapping. Halpern iterative process generates a sequence $\left\{x_{n}\right\}$ in the following manner:

$$
x_{0} \in C, \quad x_{n+1}=\alpha_{n} u+\left(1-\alpha_{n}\right) T x_{n}, \quad \forall n \geq 0,
$$

\section{Springer}

(C) 2012 Qin et al; licensee Springer. This is an Open Access article distributed under the terms of the Creative Commons Attribution License (http://creativecommons.org/licenses/by/2.0), which permits unrestricted use, distribution, and reproduction in any medium, provided the original work is properly cited. 
where $x_{0}$ is an initial and $u$ is a fixed element in C. Krasnoselski-Mann iterative process generates a sequence $\left\{x_{n}\right\}$ in the following manner:

$$
x_{0} \in C, \quad x_{n+1}=\alpha_{n} T x_{n}+\left(1-\alpha_{n}\right) x_{n}, \quad \forall n \geq 0,
$$

It is known that Algorithm (1.2) only has weak convergence even for nonexpansive mappings in infinite-dimensional Hilbert spaces (see [8] for more details and the reference therein). In many disciplines, including economics [9], image recovery [10], quantum physics [11], and control theory [12], problems arises in infinite dimension spaces. In such problems, strong convergence (norm convergence) is often much more desirable than weak convergence, for it translates the physically tangible property that the energy $\left\|x_{n}-x\right\|$ of the error between the iterate $x_{n}$ and the solution $x$ eventually becomes arbitrarily small. The important of strong convergence is also underlined in [13], where a convex function $f$ is minimized via the proximal-point algorithm: it is shown that the rate of convergence of the value sequence $\left\{f\left(x_{n}\right)\right\}$ is better when $\left\{x_{n}\right\}$ converges strongly that it converges weakly. Such properties have a direct impact when the process is executed directly in the underlying infinite dimensional space. To improve the weak convergence of Krasnoselski-Mann iterative process, so called hybrid projections have been considered (see [14-25] for more details and the references therein).

Algorithm (1.1) was initially introduced in [26]; for more details see the references therein. In [26], Halpern showed that the following conditions

(C1) $\lim _{n \rightarrow \infty}, \alpha_{n}=0$;

(C2) $\sum_{n=0}^{\infty} \alpha_{n}=\infty$,

are necessary in the sense that if Algorithm (1.1) is strongly convergent for all nonempty, closed, and convex subsets of a Hilbert space $H$ and all nonexpansive mappings on $C$, then the sequence $\left\{x_{n}\right\}$ must satisfy conditions (C1), and (C2). Due to the restriction of (C2), Algorithm (1.1) is widely believed to have slow convergence though the rate of convergence has not be determined. Thus to improve the rate of convergence of algorithm (1.1), one can not rely only on the process itself; instead, some additional step of iteration should be taken; see [27-30] and the references therein. One of the purposes of this article is to show algorithm (1.1) is strong convergence under (C1) only with the help of projections.

The purposes of this article is to study Algorithms (1.1) and (1.2) with the help of additional metric projections for the new mapping. The organization of this article is as follows. In Section 2, we provide some necessary preliminaries. In Section 3, Algorithms (1.1) and (1.2) are studied with the help of projections. Two main strong convergence theorems are established in a reflexive, strictly convex, and smooth Banach space such that both $E$ and $E^{*}$ have Kadec-Klee property. In Section 4, applications of the main results are provided.

\section{Preliminaries}

Let $H$ be a real Hilbert space, $C$ a nonempty subset of $H$, and $T: C \rightarrow C$ a mapping. The symbol $F(T)$ stands for the fixed point set of $T$. Recall the following. $T$ is said to be nonexpansive if

$$
\|T x-T y\| \leq\|x-y\|, \quad \forall x, y \in C .
$$


$T$ is said to be quasi-nonexpansive if $F(T) \neq \emptyset$, and

$$
\|p-T y\| \leq\|p-y\|, \quad \forall p \in F(T), y \in C .
$$

$T$ is said to be asymptotically nonexpansive if there exists a sequence $\left\{\mu_{n}\right\} \subset[0, \infty)$ with $\mu_{n} \rightarrow 0$ as $n \rightarrow \infty$ such that

$$
\left\|T^{n} x-T^{n} y\right\| \leq\left(1+\mu_{n}\right)\|x-y\|, \quad \forall x, y \in C, n \geq 1 .
$$

It is easy to see that a nonexpansive mapping is an asymptotically nonexpansive mapping with the sequence $\{1\}$. The class of asymptotically nonexpansive mappings was introduced by Goebel and Kirk [2]. Since 1972, a host of authors have studied the convergence of iterative algorithms for such a class of mappings.

$T$ is said to be asymptotically quasi-nonexpansive if $F(T) \neq \emptyset$, and there exists a sequence $\left\{\mu_{n}\right\} \subset[0, \infty)$ with $\mu_{n} \rightarrow 0$ as $n \rightarrow \infty$ such that

$$
\left\|p-T^{n} y\right\| \leq\left(1+\mu_{n}\right)\|p-\gamma\|, \quad \forall p \in F(T), y \in C, n \geq 1 .
$$

It is easy to see that a quasi-nonexpansive mapping is an asymptotically quasi-nonexpansive mapping with the sequence $\{1\}$.

$T$ is said to be generalized asymptotically nonexpansive if there exist two nonnegative sequences $\left\{\mu_{n}\right\} \subset[0, \infty)$ with $\mu_{n} \rightarrow 0$, and $\left\{\xi_{n}\right\} \subset[0, \infty)$ with $\xi_{n} \rightarrow 0$ as $n \rightarrow \infty$ such that

$$
\left\|T^{n} x-T^{n} y\right\| \leq\left(1+\mu_{n}\right)\|x-y\|+\xi_{n}, \quad \forall x, y \in C, \quad n \geq 1 .
$$

$T$ is said to be generalized asymptotically quasi-nonexpansive if $F(T) \neq \emptyset$, and there exist two nonnegative sequences $\left\{\mu_{n}\right\} \subset[0, \infty)$ with $\mu_{n} \rightarrow 0$, and $\left\{\xi_{n}\right\} \subset[0, \infty)$ with $\xi_{n}$ $\rightarrow 0$ as $n \rightarrow \infty$ such that

$$
\left\|T^{n} x-y\right\| \leq\left(1+\mu_{n}\right)\|x-y\|+\xi_{n}, \quad \forall x \in C, \quad y \in F(T), n \geq 1 .
$$

The class of generalized asymptotically (quasi)-nonexpansive has been considered by Shahzad and Zegeye [31] (see also Agarwal et al. [32]). It is easy to see that the class of generalized asymptotically (quasi)-nonexpansive include the class of asymptotically (quasi)-nonexpansive as a special case.

In what follows, we always assume that $E$ is a Banach space with the dual space $E^{*}$. Let $C$ be a nonempty, closed, and convex subset of $E$. We use the symbol $J$ to stand for the normalized duality mapping from $E$ to $2^{E^{*}}$ defined by

$$
J x=\left\{f^{*} \in E^{*}:\left\langle x, f^{*}\right\rangle=\|x\|^{2}=\left\|f^{*}\right\|^{2}\right\}, \quad \forall x \in E,
$$

where $\langle\cdot, \cdot\rangle$ denotes the generalized duality pairing of elements between $E$, and $E^{*}$. It is well known that if $E^{*}$ is strictly convex, then $J$ is single valued; if $E^{*}$ is reflexive, and smooth, then $J$ is single valued, and demicontinuous (see [33] for more details and the references therein).

It is also well known that if $D$ is a nonempty, closed, and convex subset of a Hilbert space $H$, and $P_{C}: H \rightarrow D$ is the metric projection from $H$ onto $D$, then $P_{D}$ is nonexpansive. This fact actually characterizes Hilbert spaces and consequently, it is not available in more general Banach spaces. In this connection, Alber [34] introduced a generalized projection operator in Banach spaces which is an analogue of the metric projection in Hilbert spaces. 
Let $U_{E}=\{x \in E:\|x\|=1\}$ be the unit sphere of $E$. $E$ is said to be strictly convex if $\left\|\frac{x+y}{2}\right\|<1$ for all $x, y \in U_{E}$ with $x \neq y$. It is said to be uniformly convex if for any $\epsilon \epsilon$ $(0,2]$ there exists $\delta>0$ such that for any $x, y \in U_{E}$,

$$
\|x-y\| \geq \varepsilon \text { implies }\left\|\frac{x+y}{2}\right\| \leq 1-\delta .
$$

It is known that a uniformly convex Banach space is reflexive and strictly convex. $E$ is said to be smooth provided $\lim _{t \rightarrow 0} \frac{\|x+t y\|-\|x\|}{t}$ exists for all $x, y \in U_{E}$. It is also said to be uniformly smooth if the limit is attained uniformly for all $x, y \in U_{E}$.

$E$ is said to enjoy Kadec-Klee property if for any sequence $\left\{x_{n}\right\} \subset E$, and $x \in E$ with $x_{n} \rightarrow x$, and $\left\|x_{n}\right\| \rightarrow\|x\|$, then $\left\|x_{n}-x\right\| \rightarrow 0$ as $n \rightarrow \infty$. For more details on Kadec-Klee property, the readers can refer to [35] and the references therein. It is well known that if $E$ is a uniformly convex Banach spaces, then $E$ enjoys Kadec-Klee property.

Let $E$ be a smooth Banach space. Consider the functional defined by

$$
\phi(x, y)=\|x\|^{2}-2\langle x, J y\rangle+\|y\|^{2}, \quad \forall x, y \in E .
$$

Notice that, in a Hilbert space $H,(2.1)$ is reduced to $\varphi(x, y)=\|x-y\|^{2}$ for all $x, y \in H$. The generalized projection $\Pi_{C}: E \rightarrow C$ is a mapping that assigns to an arbitrary point $x \in E$, the minimum point of the functional $\varphi(x, y)$; that is, $\Pi_{C} x=\bar{x}$, where $\bar{x}$ is the solution to the following minimization problem:

$$
\phi(\bar{x}, x)=\min _{y \in C} \phi(y, x) .
$$

The existence, and uniqueness of the operator $\Pi_{C}$ follow from the properties of the functional $\varphi(x, y)$, and the strict monotonicity of the mapping $J$ (see, for example, $[33,36])$. In Hilbert spaces, $\Pi_{C}=P_{C}$. It is obvious from the definition of the function $\varphi$ that

$$
(\|y\|-\|x\|)^{2} \leq \phi(y, x) \leq(\|y\|+\|x\|)^{2}, \quad \forall x, y \in E,
$$

and

$$
\phi(x, y)=\phi(x, z)+\phi(z, y)+2\langle x-z, J z-J y\rangle, \quad \forall x, y, z \in E .
$$

Remark 2.1. If $E$ is a reflexive, strictly convex, and smooth Banach space, then, for all $x, y \in E, \varphi(x, y)=0$ if and only if $x=y$. It is sufficient to show that if $\varphi(x, y)=0$, then $x=y$. From (2.2), we have $\|x\|=\|y\|$. This implies that $\langle x, J y\rangle=\|x\|^{2}=\|J y\|^{2}$. From the definition of $J$, we see that $J x=J y$. It follows that $x=y$; see $[33,36]$ for more details.

Next, we recall the following.

(1) A point $p$ in $C$ is said to be an asymptotic fixed point of $T$ [37] if $C$ contains a sequence $\left\{x_{n}\right\}$ which converges weakly to $p$ such that $\lim _{n \rightarrow \infty}\left\|x_{n}-T x_{n}\right\|=0$. The set of asymptotic fixed points of $T$ will be denoted by $\tilde{F}(T)$.

(2) $T$ is said to be relatively nonexpansive if

$$
\tilde{F}(T)=F(T) \neq \emptyset, \quad \text { and } \phi(p, T x) \leq \phi(p, x), \quad \forall x \in C, \quad p \in F(T) .
$$


(3) $T$ is said to be relatively asymptotically nonexpansive if

$$
\tilde{F}(T)=F(T) \neq \emptyset, \quad \text { and } \phi\left(p, T^{n} x\right) \leq\left(1+\mu_{n}\right) \phi(p, x), \quad \forall x \in C, p \in F(T), n \geq 1,
$$

where $\left\{\mu_{n}\right\} \subset[0, \infty)$ is a sequence such that $\mu_{n} \rightarrow 0$ as $n \rightarrow \infty$.

Remark 2.2. The class of relatively asymptotically nonexpansive mappings was first considered in Su and Qin [38] (see also, Agarwal et al. [39], and Qin et al. [40]).

(4) $T$ is said to be quasi- $\varphi$-nonexpansive if

$$
F(T) \neq \emptyset, \text { and } \phi(p, T x) \leq \phi(p, x), \quad \forall x \in C, p \in F(T) .
$$

(5) $T$ is said to be asymptotically quasi- $\varphi$-nonexpansive if there exists a sequence $\left\{\mu_{n}\right\}$ $\subset[0, \infty)$ with $\mu_{n} \rightarrow 0$ as $n \rightarrow \infty$ such that

$$
F(T) \neq \emptyset \text {, and } \phi\left(p, T^{n} x\right) \leq\left(1+\mu_{n}\right) \phi(p, x), \quad \forall x \in C, p \in F(T), n \geq 1 .
$$

Remark 2.3. The class of quasi- $\varphi$-nonexpansive mappings and the class of asymptotically quasi- $\varphi$-nonexpansive mappings were first considered in Zhou et al. [24] (see also Qin and Agarwal [18], Qin et al. [20], Qin et al. [21], Qin et al. [41]).

Remark 2.4. The class of quasi- $\varphi$-nonexpansive mappings and the class of asymptotically quasi- $\varphi$-nonexpansive mappings are more general than the class of relatively nonex-pansive mappings and the class of relatively asymptotically nonexpansive mappings. Quasi- $\varphi$-nonexpansive mappings and asymptotically quasi- $\varphi$-nonexpansive do not require $F(T)=\tilde{F}(T)$.

Remark 2.5. The class of quasi- $\varphi$-nonexpansive mappings and the class of asymptotically quasi- $\varphi$-nonexpansive mappings are generalizations of the class of quasi-nonexpansive mappings and the class of asymptotically quasi-nonexpansive mappings in Banach spaces.

In this article, we introduce and consider the following new nonlinear mapping: generalized asymptotically quasi- $\varphi$-nonexpansive mappings.

(6) $T$ is said to be an generalized asymptotically quasi- $\varphi$-nonexpansive mapping if $F(T) \neq \emptyset$, and there exist two nonnegative sequences $\left\{\mu_{n}\right\} \subset[0, \infty)$ with $\mu_{n} \rightarrow 0$, and $\left\{\xi_{n}\right\} \subset[0, \infty)$ with $\xi_{n} \rightarrow 0$ as $n \rightarrow \infty$ such that

$$
\phi\left(p, T^{n} x\right) \leq\left(1+\mu_{n}\right) \phi(p, x)+\xi_{n}, \quad \forall x \in C, p \in F(T), n \geq 1 .
$$

Remark 2.6. The class of generalized asymptotically quasi- $\varphi$-nonexpansive mappings is a generalization of the class of generalized asymptotically quasi-nonexpansive mappings in the framework of Banach spaces.

(7) $T$ is said to be asymptotically regular on $C$ if, for any bounded subset $K$ of $C$,

$$
\lim _{n \rightarrow \infty} \sup _{x \in K}\left\{\left\|T^{n+1} x-T^{n} x\right\|\right\}=0 .
$$

In order to prove our main results, we also need the following lemmas:

Lemma 2.1. [34] Let $C$ be a nonempty, closed, and convex subset of a smooth Banach space $E$, and $x \in E$. Then $x_{0}=\Pi_{C} x$ if and only if

$$
\left\langle x_{0}-y, J x-J x_{0}\right\rangle \geq 0, \quad \forall y \in C .
$$


Lemma 2.2. [34] Let $E$ be a reflexive, strictly, convex, and smooth Banach space, $C$ a nonempty, closed, and convex subset of $E$, and $x \in E$. Then

$$
\phi\left(y, \Pi_{C} x\right)+\phi\left(\Pi_{C} x, x\right) \leq \phi(y, x), \quad \forall y \in C .
$$

\section{Main results}

Theorem 3.1. Let E be a reflexive, strictly convex, and smooth Banach space such that both $E$ and $E^{*}$ have Kadec-Klee property. Let $C$ be a nonempty, closed, and convex subset of $E$. Let $\Delta$ be an index set, and $T_{i}: C \rightarrow C$ a closed, asymptotically regular, and generalized asymptotically quasi- $\varphi$-nonexpansive mapping with the sequences $\left\{\mu_{n, i}\right\}$, and $\left\{\xi_{n, i}\right\}$, for every $i \in \Delta$. Assume that $\cap_{i \in \Delta} F\left(T_{i}\right)$ is nonempty, and bounded. Let $\left\{x_{n}\right\}$ be a sequence generated in the following manner:

$$
\left\{\begin{array}{l}
x_{0} \in E, \quad \text { chosen arbitrarily, } \\
C_{1, i}=C_{,} \\
C_{1}=\cap_{i \in \Delta} C_{1, i}, \\
x_{1}=\Pi_{C_{1}} x_{0} \\
y_{n, i}=J^{-1}\left(\alpha_{n, i} J\left(T_{i}^{n} x_{n}\right)+\left(1-\alpha_{n, i}\right) J x_{n}\right), \quad n \geq 1, \quad(<\text { ?show }[\text { CSFchar }=) \\
C_{n+1, i}=\left\{u \in C_{n, i}: \phi\left(u, y_{n, i}\right) \leq \phi\left(u, x_{n}\right)+\mu_{n, i} M_{n}+\xi_{n, i}\right\}, \\
C_{n+1}=\cap_{i \in \Delta} C_{n+1, i} \\
x_{n+1}=\Pi_{C_{n+1}} x_{0}, \quad \forall n \geq 1,
\end{array}\right.
$$

where $M_{n}=\sup \left\{\varphi\left(z, x_{n}\right): z \in \cap_{i \in \Delta} F\left(T_{i}\right)\right\}$, and $\left\{\alpha_{n, i}\right\}$ are sequences in $(0,1]$ such that $\lim \inf _{n \rightarrow \infty} \alpha_{n, i}>0$. Then $\left\{x_{n}\right\}$ converges strongly to $\Pi_{\cap_{i \in \Delta} F\left(T_{i}\right)} x_{0}$, where $\Pi_{\bigcap_{i \in \Delta} F\left(T_{i}\right) \text { stands }}$ for the generalized projection from $E$ onto $\cap_{i \in \Delta} F\left(T_{i}\right)$.

Proof. The proof is split into seven steps.

Step 1. Show, for every $i \in \Delta$, that $F\left(T_{i}\right)$ is closed, and convex. This proves that $\Pi_{\bigcap_{i \in \Delta} F\left(T_{i}\right)} x_{0}$ is well defined, for every $x_{0} \in E$. On the closedness of $\cap_{i \in \Delta} F\left(T_{i}\right)$, we can easily conclude from the closedness of $T_{i}$ the desired conclusion. We only prove that $\cap_{i \in \Delta} F\left(T_{i}\right)$ is convex. Let $p_{1, i} p_{2, i} \in F\left(T_{i}\right)$, and $p_{i}=t_{i} p_{1, i}+\left(1-t_{i}\right) p_{2, i}$, where $t_{i} \in(0,1)$, for every $i \in \Delta$. We see that $p_{i}=T_{i} p_{i}$. Indeed, we see from the definition of $T_{i}$ that

$$
\phi\left(p_{1, i}, T_{i}^{n} p_{i}\right) \leq\left(1+\mu_{n, i}\right) \phi\left(p_{1, i}, p_{i}\right)+\xi_{n, i}
$$

and

$$
\phi\left(p_{2, i}, T_{i}^{n} p_{i}\right) \leq\left(1+\mu_{n, i}\right) \phi\left(p_{2, i}, p_{i}\right)+\xi_{n, i} .
$$

In view of (2.3), we obtain that

$$
\phi\left(p_{1, i}, T_{i}^{n} p_{i}\right)=\phi\left(p_{1, i}, p_{i}\right)+\phi\left(p_{i}, T_{i}^{n} p_{i}\right)+2\left\langle p_{1, i}-p_{i}, J p_{i}-J T_{i}^{n} p_{i}\right\rangle,
$$

and

$$
\phi\left(p_{2, i}, T_{i}^{n} p_{i}\right)=\phi\left(p_{2, i}, p_{i}\right)+\phi\left(p_{i}, T_{i}^{n} p_{i}\right)+2\left\langle p_{2, i}-p_{i}, J p_{i}-J T_{i}^{n} p_{i}\right\rangle .
$$

It follows from (3.1), (3.2), (3.3), and (3.4) that

$$
\phi\left(p_{i}, T_{i}^{n} p_{i}\right) \leq 2\left\langle p_{i}-p_{1, i} J p_{i}-J\left(T_{i}^{n} p_{i}\right)\right\rangle+\mu_{n, i} \phi\left(p_{1, i}, p_{i}\right)+\xi_{n, i}
$$

and

$$
\phi\left(p_{i}, T_{i}^{n} p_{i}\right) \leq 2\left\langle p_{i}-p_{2, i} J p_{i}-J\left(T_{i}^{n} p_{i}\right)\right\rangle+\mu_{n, i} \phi\left(p_{2, i}, p_{i}\right)+\xi_{n, i} .
$$


Multiplying $t_{i}$ and $\left(1-t_{i}\right)$ on the both sides of (3.5) and (3.6), respectively yields that

$$
\phi\left(p_{i}, T_{i}^{n} p_{i}\right) \leq t_{i} \mu_{n, i} \phi\left(p_{1, i}, p_{i}\right)+\left(1-t_{i}\right) \mu_{n, i} \phi\left(p_{2, i}, p_{i}\right)+\xi_{n, i}
$$

It follows that

$$
\lim _{n \rightarrow \infty} \phi\left(p_{i}, T_{i}^{n} p_{i}\right)=0 .
$$

In light of (2.2), we arrive at

$$
\lim _{n \rightarrow \infty}\left\|T_{i}^{n} p_{i}\right\|=\left\|p_{i}\right\| .
$$

It follows that

$$
\lim _{n \rightarrow \infty}\left\|J\left(T_{i}^{n} p_{i}\right)\right\|=\left\|J p_{i}\right\| .
$$

Since $E^{*}$ is reflexive, we may, without loss of generality, assume that $J\left(T_{i}^{n} p_{i}\right) \rightarrow e^{*, i} \in E^{*}$. In view of the reflexivity of $E$, we have $J(E)=E^{*}$. This shows that there exists an element $e^{i} \in E$ such that $J e^{i}=e^{* i}$. It follows that

$$
\begin{aligned}
\phi\left(p_{i} T_{i}^{n} p_{i}\right) & =\left\|p_{i}\right\|^{2}-2\left\langle p_{i} J\left(T_{i}^{n} p_{i}\right)\right\rangle+\left\|T_{i}^{n} p_{i}\right\|^{2} \\
& =\left\|p_{i}\right\|^{2}-2\left\langle p_{i} J\left(T_{i}^{n} p_{i}\right)\right\rangle+\left\|J\left(T_{i}^{n} p_{i}\right)\right\|^{2} .
\end{aligned}
$$

Taking $\lim \inf _{n \rightarrow \infty}$ on the both sides of the equality above, we obtain that

$$
\begin{aligned}
0 & \geq\left\|p_{i}\right\|^{2}-2\left\langle p_{i}, e^{*, i}\right\rangle+\left\|e^{*, i}\right\|^{2} \\
& =\left\|p_{i}\right\|^{2}-2\left\langle p_{i}, J e^{i}\right\rangle+\left\|J e^{i}\right\|^{2} \\
& =\left\|p_{i}\right\|^{2}-2\left\langle p_{i}, J e^{i}\right\rangle+\left\|e^{i}\right\|^{2} \\
& =\phi\left(p_{i}, e^{i}\right) .
\end{aligned}
$$

This implies that $p_{i}=e^{i}$, that is, $J p_{i}=e^{* i}$. It follows that $J\left(T_{i}^{n} p_{i}\right) \rightarrow J p_{i} \in E^{*}$. In view of Kadec-Klee property of $E^{*}$, we obtain from (3.8) that

$$
\lim _{n \rightarrow \infty}\left\|J\left(T_{i}^{n} p_{i}\right)-J p_{i}\right\|=0 .
$$

Since $J^{1}: E^{*} \rightarrow E$ is demicontinuous, we see that $T_{i}^{n} p_{i} \rightarrow p_{i}$. By virtue of Kadec-Klee property of $E$, we see from (3.7) that $T_{i}^{n} p_{i} \rightarrow p_{i}$ as $n \rightarrow \infty$. Hence

$$
T_{i} T_{i}^{n} p_{i}=T_{i}^{n+1} p_{i} \rightarrow p_{i}
$$

as $n \rightarrow \infty$. In view of the closedness of $T_{i}$, we can obtain that $p_{i} \in F\left(T_{i}\right)$, for every $i \in$ $\Delta$. This shows, for every $i \in \Delta$, that $F\left(T_{i}\right)$ is convex. This proves that $\cap_{i \in \Delta} F\left(T_{i}\right)$ is convex. This completes the proof of Step 1.

Step 2. Show that $C_{n}$ is closed, and convex for all $n \geq 1$. It suffices to show, for any fixed but arbitrary $i \in \Delta$, that $C_{n, i}$ is closed, and convex, for every $n \geq 1$. This can be proved by induction on $n$. It is obvious that $C_{1, i}=C$ is closed, and convex. Assume that $C_{h, i}$ is closed, and convex for some $h \geq 1$. We next prove that $C_{h+1, i}$ is closed, and convex for the same $h$. This completes the proof that $C_{n}$ is closed, and convex. The closedness of $C_{h+1, i}$ is clear. We only prove the convexness. Indeed, $\forall a, b \in C_{h+1, i}$, we see that $a, b \in C_{h, i}$, and 


$$
\phi\left(a, y_{h, i}\right) \leq \phi\left(a, x_{h}\right)+\mu_{h, i} M_{h}+\xi_{h, i}
$$

and

$$
\phi\left(b, y_{h, i}\right) \leq \phi\left(b, x_{h}\right)+\mu_{h, i} M_{h}+\xi_{h, i}
$$

Notice that (3.9), and (3.10) are equivalent to the following inequalities, respectively.

$$
2\left\langle a, J x_{h}-J y_{h, i}\right\rangle \leq\left\|x_{h}\right\|^{2}-\left\|y_{h, i}\right\|^{2}+\mu_{h, i} M_{h}+\xi_{h, i}
$$

and

$$
2\left\langle b, J x_{h}-J y_{h, i}\right\rangle \leq\left\|x_{h}\right\|^{2}-\left\|y_{h, i}\right\|^{2}+\mu_{h, i} M_{h}+\xi_{h, i}
$$

These imply that

$$
2\left\langle t a+(1-t) b, J x_{h}-J y_{h, i}\right\rangle \leq\left\|x_{h}\right\|^{2}-\left\|y_{h, i}\right\|^{2}+\mu_{h, i} M_{h}+\xi_{h, i}, \quad \forall t \in(0,1) .
$$

Since $C_{h, i}$ is convex, we see that $t a+(1-t) b \in C_{h, i}$. Notice that (3.11) is equivalent to

$$
\phi\left(t a+(1-t) b, y_{h, i}\right) \leq \phi\left(t a+(1-t) b, x_{h}\right)+\mu_{h, i} M_{h}+\xi_{h, i}
$$

This proves that $C_{h+1, i}$ is convex. This completes the proof of Step 2 .

Step 3. Show that $\cap_{i \in \Delta} F\left(T_{i}\right) \subset C_{n}$, for every $n \geq 1$. It suffices to claim that $\cap_{i \in \Delta} F\left(T_{i}\right)$ $\subset C_{n, i}$, for every $n \geq 1$, and for every $i \geq \Delta$. Note that $\cap_{i \in \Delta} F\left(T_{i}\right) \subset C_{1, i}=C$. Suppose that $\cap_{i \in \Delta} F\left(T_{i}\right) \subset C_{h, i}$ for some $h$, and for every $i \in \Delta$. Then, for all $w \in \cap_{i \in \Delta} F\left(T_{i}\right) \subset$ $C_{h, i}$, we have

$$
\begin{aligned}
\phi & \left(w, y_{h, i}\right) \\
= & \phi\left(w_{,} J^{-1}\left(\alpha_{h, i} J\left(T_{i}^{h} x_{h}\right)+\left(1-\alpha_{h, i}\right) J x_{h}\right)\right) \\
= & \|w\|^{2}-2\left\langle w, \alpha_{h, i} J\left(T_{i}^{h} x_{h}\right)+\left(1-\alpha_{h, i}\right) J x_{h}\right\rangle \\
& +\left\|\alpha_{h, i} J\left(T_{i}^{h} x_{h}\right)+\left(1-\alpha_{h, i}\right) J x_{h}\right\|^{2} \\
\leq & \|w\|^{2}-2 \alpha_{h, i}\left\langle w, J\left(T_{i}^{h} x_{h}\right)\right\rangle-2\left(1-\alpha_{h, i}\right)\left\langle w, J x_{h}\right\rangle+\alpha_{h, i}\left\|T_{i}^{h} x_{h}\right\|^{2} \\
& +\left(1-\alpha_{h, i}\right)\left\|x_{h}\right\|^{2} \\
= & \alpha_{h, i} \phi\left(w, T_{i}^{h} x_{h}\right)+\left(1-\alpha_{h, i}\right) \phi\left(w, x_{h}\right) \\
\leq & \alpha_{h, i} \mu_{h, i} \phi\left(w, x_{h}\right)+\alpha_{h, i} \xi_{h, i}+\phi\left(w, x_{h}\right) \\
\leq & \phi\left(w, x_{h}\right)+\mu_{h, i} M_{h}+\xi_{h, i}
\end{aligned}
$$

where $M_{h}=\sup _{z \in \cap_{i \in \Delta} F\left(T_{i}\right)}\left\{\phi\left(z, x_{h}\right)\right\}$.This shows that $w \in C_{h+1, i}$. This implies that $\cap_{i \in \Delta} F$ $\left(T_{i}\right) \subset C_{n}$, for every $n \geq 1$. This completes the proof of Step 3 .

Step 4. Show that $\left\{x_{n}\right\}$ is bounded. In view of $x_{n}=\Pi_{C_{n}} x_{0}$, we see that

$$
\left\langle x_{n}-z_{1} J x_{0}-J x_{n}\right\rangle \geq 0, \quad \forall z \in C_{n} .
$$

Since $\cap_{i \in \Delta} F\left(T_{i}\right) \subset C_{n}$, we arrive at

$$
\left\langle x_{n}-w, J x_{0}-J x_{n}\right\rangle \geq 0, \quad \forall w \in \cap_{i \in \Delta} F\left(T_{i}\right) .
$$


It follows from Lemma 2.2 that

$$
\begin{aligned}
\phi\left(x_{n}, x_{0}\right) & =\phi\left(\Pi_{C_{n}} x_{0}, x_{0}\right) \\
& \leq \phi\left(\Pi_{\cap_{i \in \Delta} F\left(T_{i}\right)} x_{0}, x_{0}\right)-\phi\left(\Pi_{\cap_{i \in \Delta} F\left(T_{i}\right)} x_{0}, x_{n}\right) \\
& \leq \phi\left(\Pi_{\cap_{i \in \Delta} F\left(T_{i}\right)} x_{0}, x_{0}\right) .
\end{aligned}
$$

This implies that the sequence $\left\{\varphi\left(x_{n}, x_{0}\right)\right\}$ is bounded. It follows from (2.2) that the sequence $\left\{x_{n}\right\}$ is also bounded. This completes the proof of Step 4.

Step 5. Show that $x_{n} \rightarrow \bar{x}$, where $\bar{x}$ is some point in $C$ as $n \rightarrow \infty$. Since $\left\{x_{n}\right\}$ is bounded, and the space is reflexive, we may assume that $x_{n} \rightarrow \bar{x}$. Since $C_{n}$ is closed, and convex, we see that $\bar{x} \in C_{n}$. On the other hand, we see from the weakly lower semicontinuity of the norm that

$$
\begin{aligned}
\phi\left(\bar{x}, x_{0}\right) & =\|\bar{x}\|^{2}-2\left\langle\bar{x}, J x_{0}\right\rangle+\left\|x_{0}\right\|^{2} \\
& \leq \liminf _{n \rightarrow \infty}\left(\left\|x_{n}\right\|^{2}-2\left\langle x_{n}, J x_{0}\right\rangle+\left\|x_{0}\right\|^{2}\right) \\
& =\liminf _{n \rightarrow \infty} \phi\left(x_{n}, x_{0}\right) \\
& \leq \limsup _{n \rightarrow \infty} \phi\left(x_{n}, x_{0}\right) \\
& \leq \phi\left(\bar{x}, x_{0}\right)
\end{aligned}
$$

which implies that $\phi\left(x_{n}, x_{0}\right) \rightarrow\left(\bar{x}, x_{0}\right)$ as $n \rightarrow \infty$. Hence, $\left\|x_{n}\right\| \rightarrow\|\bar{x}\|$ as $n \rightarrow \infty$. In view of Kadec-Klee property of $E$, we see that $x_{n} \rightarrow \bar{x}$ as $n \rightarrow \infty$. This completes the proof of Step 5.

Step 6. Show that $\bar{x} \in \cap_{i \in \Delta} F\left(T_{i}\right)$. In view of construction of $x_{n+1}=\Pi_{\cap_{i \in \Delta} F\left(T_{i}\right)} x_{0} \in C_{n+1} \subset C_{n}$, we arrive at

$$
\begin{aligned}
\phi\left(x_{n+1}, x_{n}\right) & =\phi\left(x_{n+1}, \Pi_{C_{n}} x_{0}\right) \\
& \leq \phi\left(x_{n+1}, x_{0}\right)-\phi\left(\Pi_{C_{n}} x_{0}, x_{0}\right) \\
& =\phi\left(x_{n+1}, x_{0}\right)-\phi\left(x_{n}, x_{0}\right) .
\end{aligned}
$$

Since $x_{n}=\Pi_{C_{n}} x_{0}$, and $x_{n+1}=\Pi_{C_{n+1}} x_{0} \in C_{n+1} \subset C_{n}$, we arrive at $\varphi\left(x_{n}, x_{0}\right) \leq \varphi\left(x_{n+1}, x_{0}\right)$, $\forall n \geq 1$. This shows that $\left\{\varphi\left(x_{n}, x_{0}\right)\right\}$ is nondecreasing. It follows from the boundedness that $\lim _{n \rightarrow \infty} \varphi\left(x, x_{0}\right)$ exists. It follows that

$$
\lim _{n \rightarrow \infty} \phi\left(x_{n+1}, x_{n}\right)=0 \text {. }
$$

Since $x_{n+1}=\Pi_{C_{n+1}} x_{0} \in C_{n+1}$, we arrive at

$$
\phi\left(x_{n+1}, y_{n, i}\right) \leq \phi\left(x_{n+1}, x_{n}\right)+\mu_{n, i} M_{n}+\xi_{n, i} .
$$

This in turn implies from (3.13) that

$$
\lim _{n \rightarrow \infty} \phi\left(x_{n+1}, y_{n, i}\right)=0 \text {. }
$$

In view of (2.2), we see that

$$
\lim _{n \rightarrow \infty}\left(\left\|x_{n+1}\right\|-\left\|y_{n, i}\right\|\right)=0 .
$$

This in turn implies that

$$
\lim _{n \rightarrow \infty}\left\|y_{n, i}\right\|=\|\bar{x}\| .
$$


It follows that

$$
\lim _{n \rightarrow \infty}\left\|J y_{n, i}\right\|=\|J \bar{x}\| .
$$

This implies that $\left\{J y_{n, i}\right\}$ is bounded. Note that both $E$ and $E^{*}$ are reflexive. We may assume that $J y_{n, i} \rightarrow y^{* i} \in E^{*}$, for every $i \in \Delta$. In view of the reflexivity of $E$, we see that $J(E)=E^{*}$. This shows that there exists an element $y^{i} \in E$ such that $J y^{i}=y^{*, i}$. It follows that

$$
\begin{aligned}
\phi\left(x_{n+1}, y_{n, i}\right) & =\left\|x_{n+1}\right\|^{2}-2\left\langle x_{n+1}, J y_{n, i}\right\rangle+\left\|y_{n, i}\right\|^{2} \\
& =\left\|x_{n+1}\right\|^{2}-2\left\langle x_{n+1}, J y_{n, i}\right\rangle+\left\|J y_{n, i}\right\|^{2} .
\end{aligned}
$$

Taking lim $\inf _{n \rightarrow \infty}$ on the both sides of the equality above yields that

$$
\begin{aligned}
0 & \geq\|\bar{x}\|^{2}-2\left\langle\bar{x}, y^{*, i}\right\rangle+\left\|y^{*, i}\right\|^{2} \\
& =\|\bar{x}\|^{2}-2\left\langle\bar{x}, J y^{i}\right\rangle+\left\|J y^{i}\right\|^{2} \\
& =\|\bar{x}\|^{2}-2\left\langle\bar{x}, J y^{i}\right\rangle+\left\|y^{i}\right\|^{2} \\
& =\phi\left(\bar{x}, y^{i}\right) .
\end{aligned}
$$

That is, $\bar{x}=y^{i}$, which in turn implies that $\gamma^{*, i}=J \bar{x}$, for every $i \in \Delta$. It follows that $J y_{n, i} \rightarrow J \bar{x} \in E^{*}$, for every $i \in \Delta$. Since $E^{*}$ enjoys Kadec-Klee property, we obtain from (3.15) that

$$
\lim _{n \rightarrow \infty} J y_{n, i}=J \bar{x}
$$

Notice that

$$
\left\|J x_{n}-J y_{n, i}\right\| \leq\left\|J x_{n}-J \bar{x}\right\|+\left\|J \bar{x}-J y_{n, i}\right\| .
$$

It follows that

$$
\lim _{n \rightarrow \infty}\left\|J x_{n}-J y_{n, i}\right\|=0
$$

Notice from $(\Upsilon)$ that

$$
J x_{n}-J y_{n, i}=\alpha_{n, i}\left(J\left(T_{i}^{n} x_{n}\right)-J x_{n}\right) .
$$

In view of the assumption that $\lim \inf _{n \rightarrow \infty} \alpha_{n, i}>0$, we arrive at

$$
\lim _{n \rightarrow \infty}\left\|J\left(T_{i}^{n} x_{n}\right)-J x_{n}\right\|=0 .
$$

Notice that

$$
\left\|J\left(T_{i}^{n} x_{n}\right)-J \bar{x}\right\| \leq\left\|J\left(T_{i}^{n} x_{n}\right)-J x_{n}\right\|+\left\|J x_{n}-J \bar{x}\right\| .
$$

This implies from (3.17) that

$$
\lim _{n \rightarrow \infty}\left\|J\left(T_{i}^{n} x_{n}\right)-J \bar{x}\right\|=0 .
$$

The demi-continuity of $J^{-1}: E^{*} \rightarrow E$ implies that $T_{i}^{n} x_{n} \rightarrow \bar{x}$, for every $i \in \Delta$. Note that

$$
\left|\left\|T_{i}^{n} x_{n}\right\|-\|\bar{x}\|\right|=\left|\left\|J\left(T_{i}^{n} x_{n}\right)\right\|-\|J \bar{x}\|\right| \leq\left\|J\left(T_{i}^{n} x_{n}\right)-J \bar{x}\right\| .
$$


In view of (3.18), we see that $\left\|T_{i}^{n} x_{n}\right\| \rightarrow\|\bar{x}\|$, for every $i \in \Delta$ as $n \rightarrow \infty$. Since $E$ enjoy Kadec-Klee property, we obtain that

$$
\lim _{n \rightarrow \infty}\left\|T_{i}^{n} x_{n}-\bar{x}\right\|=0 .
$$

Notice that

$$
\left\|T_{i}^{n+1} x_{n}-\bar{x}\right\| \leq\left\|T_{i}^{n+1} x_{n}-T_{i}^{n} x_{n}\right\|+\left\|T_{i}^{n} x_{n}-\bar{x}\right\| .
$$

It follows from the asymptotic regularity of $T_{i}$, and (3.19) that

$$
\lim _{n \rightarrow \infty}\left\|T_{i}^{n+1} x_{n}-\bar{x}\right\|=0,
$$

that is, $T_{i} T_{i}^{n} x_{n}-\bar{x} \rightarrow 0$ as $n \rightarrow \infty$. It follows from the closedness of $T_{i}$ that $T_{i} \bar{x}=\bar{x}$, for every $i \in \Delta$. This completes the proof of Step 6 .

Step 7. Show that $\bar{x}=\Pi_{\bigcap_{i \in \Delta} F\left(T_{i}\right)} x_{0}$. Letting $n \rightarrow \infty$ in (3.12), we arrive at

$$
\left\langle\bar{x}-w, J x_{0}-J \bar{x}\right\rangle \geq 0, \quad \forall w \in \cap_{i \in \Delta} F\left(T_{i}\right) .
$$

It follows from Lemma 2.1 that $\bar{x}=\Pi_{\bigcap_{i \in \Delta} F\left(T_{i}\right)} x_{0}$. This completes the proof of Step 7. The proof of Theorem 3.1 is completed.

Remark 3.2. Comparing Theorem 3.1 with Theorem 2.1 in Qin et al. [21], we have the following:

(a) extend the mapping from the class of asymptotically quasi- $\varphi$-nonexpansive mappings to the class of generalized asymptotically quasi- $\varphi$-nonexpansive mappings;

(b) extend the mapping from a single mapping to a family of mappings;

(c) extend the space from a uniformly smooth, and strictly convex Banach space which also enjoys the Kadec-Klee property to a reflexive, strictly convex, and smooth Banach space such that both $E$ and $E^{*}$ have Kadec-Klee property.

Remark 3.3. Strictly convex, reflexive, and smooth Musielak-Orlicz spaces satisfy the restrictions imposed on the framework of the spaces [35], while, in general, these spaces need not to be uniformly convex or uniformly smooth.

For a single mapping, we can easily conclude the following.

Corollary 3.4. Let $E$ be a reflexive, strictly convex, and smooth Banach space such that both $E$ and $E^{*}$ have Kadec-Klee property. Let $C$ be a nonempty, closed, and convex subset of E. Let $T: C \rightarrow C$ be a closed, asymptotically regular, and generalized asymptotically quasi- $\varphi$-nonexpansive mapping with the sequences $\left\{\mu_{n}\right\}$, and $\left\{\xi_{n}\right\}$. Assume that $F(T)$ is nonempty, and bounded. Let $\left\{x_{n}\right\}$ be a sequence generated in the following manner:

$$
\left\{\begin{array}{l}
x_{0} \in E, \quad \text { chosen arbitrarily, } \\
C_{1}=C_{1} \\
x_{1}=\Pi_{C_{1}} x_{0} \\
y_{n}=J^{-1}\left(\alpha_{n} J\left(T^{n} x_{n}\right)+\left(1-\alpha_{n}\right) J x_{n}\right), \quad n \geq 1, \\
C_{n+1}=\left\{u \in C_{n}: \phi\left(u, y_{n}\right) \leq \phi\left(u, x_{n}\right)+\mu_{n} M_{n}+\xi_{n}\right\}, \\
x_{n+1}=\Pi_{C_{n+1}} x_{0}, \quad \forall n \geq 1 .
\end{array}\right.
$$


where $M_{n}=\sup \left\{\varphi\left(z, x_{n}\right): z \in F(T)\right\}$, and $\left\{\alpha_{n}\right\}$ is a sequence in $(0,1]$ such that lim $\inf _{n \rightarrow \infty} \alpha_{n}>0$. Then $\left\{x_{n}\right\}$ converges strongly to $\Pi_{F(T)} x_{0}$, where $\Pi_{F(T)}$ stands for the generalized projection from $E$ onto $F(T)$.

If $\alpha_{n}=1$, then Theorem 3.1 is reduced to the following.

Corollary 3.5. Let $E$ be a reflexive, strictly convex, and smooth Banach space such that both $E$ and $E^{*}$ have Kadec-Klee property. Let $C$ be a nonempty, closed, and convex subset of $E$. Let $\Delta$ be an index set, and $T_{i}: C \rightarrow C$ a closed, asymptotically regular, and generalized asymptotically quasi- $\varphi$-nonexpansive mapping with the sequences $\left\{\mu_{n, i}\right\}$, and $\left\{\xi_{n, i}\right\}$, for every $i \in \Delta$. Assume that $\cap_{i \in \Delta} F\left(T_{i}\right)$ is nonempty, and bounded. Let $\left\{x_{n}\right\}$ be a sequence generated in the following manner:

$$
\left\{\begin{array}{l}
x_{0} \in E, \quad \text { chosen arbitrarily, } \\
C_{1, i}=C, \\
C_{1}=\cap_{i \in \Delta} C_{1, i}, \\
x_{1}=\prod_{C_{1}} x_{0}, \\
C_{n+1, i}=\left\{u \in C_{n, i}: \phi\left(u, T_{i}^{n} x_{n}\right) \leq \phi\left(u, x_{n}\right)+\mu_{n, i} M_{n}+\xi_{n, i}\right\} \\
C_{n+1}=\cap_{i \in \Delta} C_{n+1, i} \\
x_{n+1}=\prod_{C_{n+1}} x_{0}, \quad \forall n \geq 1,
\end{array}\right.
$$

where $M_{n}=\sup \left\{\varphi\left(z, x_{n}\right): z \in \cap_{i \in \Delta} F\left(T_{i}\right)\right\}$, and $\left\{\alpha_{n, i}\right\}$ are sequences in $(0,1]$ such that $\lim \inf _{n \rightarrow \infty} \alpha_{n, i}>0$. Then $\left\{x_{n}\right\}$ converges strongly to $\Pi_{\cap_{i \in \Delta} F\left(T_{i}\right)} x_{0}$, where $\Pi_{\bigcap_{i \in \Delta} F\left(T_{i}\right) \text { stands }}$ for the generalized projection from $E$ onto $\cap_{i \in \Delta} F\left(T_{i}\right)$.

In the framework of Hilbert spaces, Theorem 3.1 is reduced to the following.

Corollary 3.6. Let $C$ be a nonempty, closed, and convex subset of a Hilbert space E. Let $\Delta$ be an index set, and $T_{i}: C \rightarrow C$ a closed, asymptotically regular, and generalized asymptotically quasi-nonexpansive mapping with the sequences $\left\{\mu_{n, i}\right\}$, and $\left\{\xi_{n, i}\right\}$, for every $i \in \Delta$. Assume that $\cap_{i \in \Delta} F\left(T_{i}\right)$ is nonempty, and bounded. Let $\left\{x_{n}\right\}$ be a sequence generated in the following manner:

$$
\left\{\begin{array}{l}
x_{0} \in E, \quad \text { chosen arbitrarily, } \\
C_{1, i}=C_{\prime} \\
C_{1}=\cap_{i \in \Delta} C_{1, i} \\
x_{1}=P_{C_{1}} x_{0} \\
y_{n, i}=\alpha_{n, i} T_{i}^{n} x_{n}+\left(1-\alpha_{n, i}\right) x_{n}, \quad n \geq 1, \\
C_{n+1, i}=\left\{u \in C_{n, i}:\left\|u-y_{n, i}\right\|^{2} \leq\left\|u-x_{n}\right\|^{2}+\mu_{n, i} M_{n}+\xi_{n, i}\right\} \\
C_{n+1}=\cap_{i \in \Delta} C_{n+1, i} \\
x_{n+1}=P_{C_{n+1}} x_{0}, \quad \forall n \geq 1
\end{array}\right.
$$

where $M_{n}=\sup \left\{\left\|z-x_{n}\right\|^{2}: z \in \cap_{i \in \Delta} F\left(T_{i}\right)\right\}$, and $\left\{\alpha_{n, i}\right\}$ are sequences in $(0,1]$ such that $\lim \inf _{n \rightarrow \infty} \alpha_{n, i}>0$. Then $\left\{x_{n}\right\}$ converges strongly to $P_{\cap_{i \in \Delta} F\left(T_{i}\right)} x_{0}$, where $P_{\bigcap_{i \in \Delta} F\left(T_{i}\right) \text { stands for }}$ the metric projection from $E$ onto $\cap_{i \in \Delta} F\left(T_{i}\right)$.

For a single mapping, we can easily conclude the following.

Corollary 3.7. Let $C$ be a nonempty, closed, and convex subset of a Hilbert space E. Let $T: C \rightarrow C$ be a closed, asymptotically regular, and generalized asymptotically quasi-nonexpansive mapping with the sequences $\left\{\mu_{n}\right\}$, and $\left\{\xi_{n}\right\}$. Assume that $F(T)$ is nonempty, and bounded. Let $\left\{x_{n}\right\}$ be a sequence generated in the following manner: 


$$
\left\{\begin{array}{l}
x_{0} \in E, \quad \text { chosen arbitrarily, } \\
C_{1}=C_{,} \\
x_{1}=P_{C_{1}} x_{0} \\
y_{n, i}=\alpha_{n} T^{n} x_{n}+\left(1-\alpha_{n}\right) x_{n}, \quad n \geq 1, \\
C_{n+1}=\left\{u \in C_{n}:\left\|u-y_{n}\right\|^{2} \leq\left\|u-x_{n}\right\|^{2}+\mu_{n} M_{n}+\xi_{n}\right\} \\
x_{n+1}=P_{C_{n+1}} x_{0}, \quad \forall n \geq 1,
\end{array}\right.
$$

where $M_{n}=\sup \left\{\left\|z-x_{n}\right\|^{2}: z \in \cap_{i \in \Delta} F\left(T_{i}\right)\right\}$, and $\left\{\alpha_{n}\right\}$ is a sequence in $(0,1]$ such that $\lim \inf _{n \rightarrow \infty} \alpha_{n}>0$. Then $\left\{x_{n}\right\}$ converges strongly to $P_{F(T)} x_{0}$, where $P_{F(T)}$ stands for the metric projection from $E$ onto $F(T)$.

Next, we turn our attention to Algorithm (1.1).

Theorem 3.8. Let $E$ be a reflexive, strictly convex, and smooth Banach space such that both $E$ and $E^{*}$ have Kadec-Klee property. Let $C$ be a nonempty, closed, and convex subset of $E$. Let $\Delta$ be an index set, and $T_{i}: C \rightarrow C$ a closed, asymptotically regular, and generalized asymptotically quasi- $\varphi$-nonexpansive mapping with the sequences $\left\{\mu_{n, i}\right\}$, and $\left\{\xi_{n, i}\right\}$, for every $i \in \Delta$. Assume that $\cap_{i \in \Delta} F\left(T_{i}\right)$ is nonempty, and bounded. Let $\left\{x_{n}\right\}$ be a sequence generated in the following manner:

$$
\left\{\begin{array}{l}
x_{0} \in E, \quad \text { chosen arbitrarily, } \\
C_{1, i}=C_{,} \\
C_{1}=\cap_{i \in \Delta} C_{1, i} \\
x_{1}=\Pi_{C_{1}} x_{0} \\
y_{n, i}=J^{-1}\left(\alpha_{n, i} J x_{1}+\left(1-\alpha_{n, i}\right) J\left(T_{i}^{n} x_{n}\right)\right), \quad n \geq 1, \\
C_{n+1, i}=\left\{u \in C_{n, i}: \phi\left(u, y_{n, i}\right) \leq \phi\left(u, x_{n}\right)+\alpha_{n, i} M+\xi_{n, i}\right\} \\
C_{n+1}=\bigcap_{i \in \Delta} C_{n+1, i} \\
x_{n+1}=\prod_{C_{n+1}} x_{1}, \quad \forall n \geq 1,
\end{array}\right.
$$

where $M=\sup _{z \in \cap_{i \in \Delta} F\left(T_{i}\right)}\left\{\phi\left(z, x_{1}\right)\right\}$, and $\left\{\alpha_{n, i}\right\}$ are sequences in $(0,1)$ such that $\lim _{n \rightarrow \infty}$ $\alpha_{n, i}=0$. Assume that $\mu_{n, i} \leq \frac{\alpha_{n, i}}{1-\alpha_{n, i}}$. Then $\left\{x_{n}\right\}$ converges strongly to $\Pi_{\cap_{i \in \Delta} F\left(T_{i}\right)} x_{1}$, where

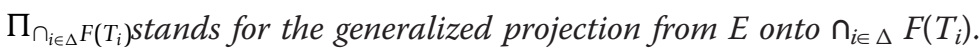

Proof. In view of the proof of Theorem 3.1, we show the difference only. From the proof of Step 1 of Theorem 3.1, we see that $\cap_{i \in \Delta} F\left(T_{i}\right)$ is closed, and convex.

Next, we show that $C_{n}$ is closed, and convex for all $n \geq 1$. It suffices to show, for any fixed but arbitrary $i \in \Delta$, that $C_{n, i}$ is closed, and convex, for every $n \geq 1$. This can be proved by induction on $n$. It is obvious that $C_{1, i}=C$ is closed, and convex. Assume that $C_{h, i}$ is closed, and convex for some $h \geq 1$. We next prove that $C_{h+1, i}$ is closed, and convex for the same $h$. This completes the proof that $C_{n}$ is closed, and convex. The closedness of $C_{h+1, i}$ is clear. We only prove the convexness. Indeed, $\forall a, b \in C_{h+1, i}$, we see that $a, b \in C_{h, i}$, and

$$
\phi\left(a, y_{h, i}\right) \leq \phi\left(a, x_{h}\right)+\alpha_{h, i} M+\xi_{h, i}
$$

and

$$
\phi\left(b, y_{h, i}\right) \leq \phi\left(b, x_{h}\right)+\alpha_{h, i} M+\xi_{h, i} .
$$

Notice that (3.20), and (3.21) are equivalent to the following inequalities, respectively.

$$
2\left\langle a, J x_{h}-J y_{h, i}\right\rangle \leq\left\|x_{h}\right\|^{2}-\left\|y_{h, i}\right\|^{2}+\alpha_{h, i} M+\xi_{h, i}
$$


and

$$
2\left\langle b, J x_{h}-J y_{h, i}\right\rangle \leq\left\|x_{h}\right\|^{2}-\left\|y_{h, i}\right\|^{2}+\alpha_{h, i} M+\xi_{h, i} .
$$

These imply that

$$
2\left\langle t a+(1-t) b, J x_{h}-J y_{h, i}\right\rangle \leq\left\|x_{h}\right\|^{2}-\left\|y_{h, i}\right\|^{2}+\alpha_{h, i} M+\xi_{h, i}, \quad \forall t \in(0,1) .
$$

Since $C_{h, i}$ is convex, we see that $t a+(1-t) b \in C_{h, i}$. Notice that (3.22) is equivalent to

$$
\phi\left(t a+(1-t) b, y_{h, i}\right) \leq \phi\left(t a+(1-t) b, x_{h}\right)+\alpha_{h, i} M+\xi_{h, i} .
$$

This proves that $C_{h+1, i}$ is convex. This completes the proof that $C_{n}$ is closed, and convex for all $n \geq 1$.

Next, we show that $\cap_{i \in \Delta} F\left(T_{i}\right) \subset C_{n}$, for every $n \geq 1$. It suffices to claim that $\cap_{i \in \Delta} F$ $\left(T_{i}\right) \subset C_{n, i}$, for every $n \geq 1$, and for every $i \geq \Delta$. Note that $\cap_{i \in \Delta} F\left(T_{i}\right) \subset C_{1, i}=C$. Suppose that $\cap_{i \in \Delta} F\left(T_{i}\right) \subset C_{h, i}$ for some $h$, and for every $i \in \Delta$. Then, for $\forall w \in \cap_{i \in \Delta} F\left(T_{i}\right)$ $\subset C_{h, i}$, we obtain from the restriction $\mu_{n, i} \leq \frac{\alpha_{n, i}}{1-\alpha_{n, i}}$ that

$$
\begin{aligned}
& \phi\left(w, y_{h, i}\right) \\
& =\phi\left(w_{,} J^{-1}\left(\alpha_{h, i} J x_{1}+\left(1-\alpha_{h, i}\right) J\left(T_{i}^{h} x_{h}\right)\right)\right) \\
& =\|w\|^{2}-2\left\langle w, \alpha_{h, i} J x_{1}+\left(1-\alpha_{h, i}\right) J\left(T_{i}^{h} x_{h}\right)\right\rangle+\left\|\alpha_{h, i} J x_{1}+\left(1-\alpha_{h, i}\right) J\left(T_{i}^{h}\right)\right\|^{2} \\
& \leq\|w\|^{2}-2 \alpha_{h, i}\left\langle w, J x_{1}\right\rangle-2\left(1-\alpha_{h, i}\right)\left\langle w, J\left(T_{i}^{h} x_{h}\right)\right\rangle+\alpha_{h, i}\left\|x_{1}\right\|^{2}+\left(1-\alpha_{h, i}\right)\left\|T_{i}^{h} x_{h}\right\|^{2} \\
& =\alpha_{h, i} \phi\left(w, x_{1}\right)+\left(1-\alpha_{h, i}\right) \phi\left(w, T_{i}^{h} x_{h}\right) \\
& \leq \phi\left(w, x_{h}\right)+\alpha_{h, i} \phi\left(w, x_{1}\right)-\left(\alpha_{h, i}-\left(1-\alpha_{h, i}\right) \mu_{h, i}\right) \phi\left(w, x_{h}\right)+\xi_{h, i} \\
& \leq \phi\left(w, x_{h}\right)+\alpha_{h, i} M+\xi_{h, i}
\end{aligned}
$$

where $M=\sup _{z \in \cap_{i \in \Delta} F\left(T_{i}\right)}\left\{\phi\left(z, x_{1}\right)\right\}$. This shows that $w \in C_{h+1, i}$. This implies that $\mathrm{\cap}_{i \in \Delta} F\left(T_{i}\right) \subset C_{n}$, for every $n \geq 1$. This completes the proof that $\mathrm{\cap}_{i \in \Delta} F\left(T_{i}\right) \subset C_{n}$, for every $n \geq 1$.

In the light of the proof of Step 4 of Theorem 3.1, we find that $\left\{x_{n}\right\}$ is bounded. It follows the proof of Step 5 of Theorem 3.1 that $x_{n} \rightarrow \bar{x} \in$ Cas $n \rightarrow \infty$. Next, we show that $\bar{x} \in \cap_{i \in \Delta} F\left(T_{i}\right)$. In view of the proof of Step 6 of Theorem 3.1, we find that

$$
\lim _{n \rightarrow \infty} \phi\left(x_{n+1}, x_{n}\right)=0 \text {. }
$$

Since $x_{n+1}=\Pi_{C_{n+1}} x_{0} \in C_{n+1}$, we arrive at

$$
\phi\left(x_{n+1}, y_{n, i}\right) \leq \phi\left(x_{n+1}, x_{n}\right)+\alpha_{n, i} M+\xi_{n, i} \text {. }
$$

This in turn implies that

$$
\lim _{n \rightarrow \infty} \phi\left(x_{n+1}, y_{n, i}\right)=0 \text {. }
$$

In view of the proof of Step 6 of Theorem 3.1, we find that

$$
\lim _{n \rightarrow \infty}\left\|J x_{n}-J y_{n, i}\right\|=0
$$


Notice from (YY) that

$$
\left\|J\left(T_{i}^{n} x_{n}\right)-J x_{n}\right\| \leq \frac{1}{1-\alpha_{n, i}}\left\|J y_{n, i}-J x_{n}\right\|+\frac{\alpha_{n, i}}{1-\alpha_{n, i}}\left\|J x_{n}-J x_{1}\right\| .
$$

In view of the assumption that $\lim _{n \rightarrow \infty} \alpha_{n, i}=0, \forall i \in \Delta$, we find from (3.25) that

$$
\lim _{n \rightarrow \infty}\left\|J\left(T_{i}^{n} x_{n}\right)-J x_{n}\right\|=0 .
$$

Next, following Steps 6 and 7, we can easily conclude the desired conclusion. This completes the proof of Theorem 3.8.

Remark 3.9. In view of the mappings, and the framework of the spaces, we see that Theorem 3.8 can be viewed as a generalization of the corresponding results announced in Cho et al. [27], Qin et al. [28], and Qin and Su [29].

For a single mapping, we obtain from Theorem 3.8 the following.

Corollary 3.10. Let $E$ be a reflexive, strictly convex, and smooth Banach space such that both $E$ and $E^{*}$ have Kadec-Klee property. Let $C$ be a nonempty, closed, and convex subset of E. Let $T: C \rightarrow C$ a closed, asymptotically regular, and generalized asymptotically quasi- $\varphi$-nonexpansive mapping with the sequences $\left\{\mu_{n}\right\}$, and $\left\{\xi_{n}\right\}$. Assume that $F$ (T) is nonempty, and bounded. Let $\left\{x_{n}\right\}$ be a sequence generated in the following manner:

$$
\left\{\begin{array}{l}
x_{0} \in E, \quad \text { chosen arbitrarily, } \\
C_{1}=C_{,} \\
x_{1}=\Pi_{C_{1}} x_{0}, \\
y_{n}=J^{-1}\left(\alpha_{n} J x_{1}+\left(1-\alpha_{n}\right) J\left(T^{n} x_{n}\right)\right), \quad n \geq 1, \\
C_{n+1}=\left\{u \in C_{n}: \phi\left(u, y_{n}\right) \leq\left(u, x_{n}\right)+\alpha_{n} M+\xi_{n}\right\}, \\
x_{n+1}=\Pi_{C_{n+1}} x_{1}, \quad \forall n \geq 1,
\end{array}\right.
$$

where $M=\sup _{\mathcal{A} F(T)}\left\{\varphi\left(z, x_{1}\right)\right\}$, and $\left\{\alpha_{n}\right\}$ is a sequence in $(0,1)$ such that $\lim _{n \rightarrow \infty} \alpha_{n}=0$. Assume that $\mu_{n} \leq \frac{\alpha_{n}}{1-\alpha_{n}}$. Then $\left\{x_{n}\right\}$ converges strongly to $\Pi_{F(T)} x_{1}$, where $\Pi_{F(T)}$ stands for the generalized projection from $E$ onto $F(T)$.

In the framework of Hilbert spaces, Theorem 3.8 is reduced to the following.

Corollary 3.11. Let $C$ be a nonempty, closed, and convex subset of a Hilbert space $E$. Let $\Delta$ be an index set, and $T_{i}: C \rightarrow C$ a closed, asymptotically regular, and generalized asymptotically quasi-nonexpansive mapping with the sequences $\left\{\mu_{n, i}\right\}$, and $\left\{\xi_{n, i}\right\}$, for every $i \in \Delta$. Assume that $\cap_{i \in \Delta} F\left(T_{i}\right)$ is nonempty, and bounded. Let $\left\{x_{n}\right\}$ be a sequence generated in the following manner:

$$
\left\{\begin{array}{l}
x_{0} \in E, \quad \text { chosen arbitrarily, } \\
C_{1, i}=C_{,} \\
C_{1}=\cap_{i \in \Delta} C_{1, i}, \\
x_{1}=P_{C_{1}} x_{0} \\
y_{n, i}=\alpha_{n, i} x_{1}+\left(1-\alpha_{n, i}\right) T_{i}^{n} x_{n,} \quad n \geq 1, \\
C_{n+1, i}=\left\{u \in C_{n, i}:\left\|u-y_{n, i}\right\|^{2} \leq\left\|u-x_{n}\right\|^{2}+\alpha_{n, i} M+\xi_{n, i}\right\}, \\
C_{n+1}=\bigcap_{i \in \Delta} C_{n+1, i}, \\
x_{n+1}=P_{C_{n+1}} x_{1}, \quad \forall n \geq 1,
\end{array}\right.
$$

where $M=\sup _{z \in \cap_{i \in \Delta} F\left(T_{i}\right)}\left\{\left\|z-x_{1}\right\|^{2}\right\}$, and $\left\{\alpha_{n, i}\right\}$ are sequences in $(0,1)$ such that $\lim _{n \rightarrow \infty} \alpha_{n, i}=0$. Assume that $\mu_{n, i} \leq \frac{\alpha_{n, i}}{1-\alpha_{n, i}}$.Then $\left\{x_{n}\right\}$ converges strongly to $P_{\cap_{i \in \Delta} F\left(T_{i}\right)} x_{1}$,

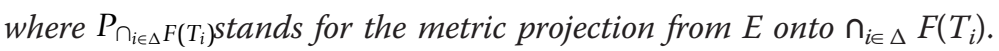


Remark 3.12. Comparing with Theorem 3.1 in Martinez-Yanes and Xu [30], we have the following:

(a) improve the mapping from nonexpansive mappings to asymptotically quasinonexpansive mappings;

(b) improve the mapping from a single mapping to a family of mappings;

(b) the hybrid projection in Corollary 3.1 is different with the one in [30].

For a single mapping, we obtain from Corollary 3.11 the following.

Corollary 3.13. Let $C$ be a nonempty, closed, and convex subset of a Hilbert space E. Let $T: C \rightarrow C$ a closed, asymptotically regular, and generalized asymptotically quasinonexpansive mapping with the sequences $\left\{\mu_{n}\right\}$, and $\left\{\xi_{n}\right\}$. Assume that $F(T)$ is nonempty, and bounded. Let $\left\{x_{n}\right\}$ be a sequence generated in the following manner:

$$
\left\{\begin{array}{l}
x_{0} \in E, \quad \text { chosen arbitrarily, } \\
C_{1}=C, \\
x_{1}=P_{C_{1}} x_{0} \\
y_{n}=\alpha_{n} x_{1}+\left(1-\alpha_{n}\right) T^{n} x_{n}, \quad n \geq 1, \\
C_{n+1}=\left\{u \in C_{n}:\left\|u-y_{n}\right\|^{2} \leq\left\|u-x_{n}\right\|^{2}+\alpha_{n} M+\xi_{n}\right\} \\
x_{n+1}=P_{C_{n+1}} x_{1}, \quad \forall n \geq 1,
\end{array}\right.
$$

where $M=\sup _{z \in F(T)}\left\{\left\|z-x_{1}\right\|^{2}\right\}$, and $\left\{\alpha_{n}\right\}$ is a sequence in $(0,1)$ such that $\lim _{n \rightarrow \infty} \alpha_{n}=$ 0 . Assume that $\mu_{n} \leq \frac{\alpha_{n}}{1-\alpha_{n}}$. Then $\left\{x_{n}\right\}$ converges strongly to $P_{F(T)} x_{1}$, where $P_{F(T)}$ stands for the metric projection from $E$ onto $F(T)$.

\section{Applications}

First, we consider the problem of approximating a common minimizer of a family of proper, lower semicontinuous, and convex functionals.

Let $E$ be a Banach space with the dual $E^{*}$. For a proper lower semicontinuous convex function $f: E \rightarrow(-\infty, \infty]$, the subdifferential mapping $\partial f \subset E \times E^{*}$ of $f$ is defined by

$$
\partial f(x)=\left\{x^{*} \in E^{*}: f(x)+\left\langle y-x, x^{*}\right\rangle \leq f(y), \forall y \in E\right\}, \quad \forall x \in E .
$$

Rockafellar [42] proved that $\partial f$ is a maximal monotone operator. It is easy to verify that $0 \in \partial f(v)$ if and only if $f(v)=\min _{x \in E} f(x)$.

Theorem 4.1. Let $E$ be a reflexive, strictly convex, and smooth Banach space such that both E and $E^{*}$ have Kadec-Klee property. Let $C$ be a nonempty, closed, and convex subset of $E$. Let $\Delta$ be an index set, and $f_{i}: C \rightarrow C$ a proper, lower semicontinuous, and convex functionals, for every $i \in \Delta$. Assume that $\mathrm{n}_{i \in \Delta}\left(\partial f_{i}\right)^{-1}(0)$ is nonempty. Let $\left\{x_{n}\right\}$ be a sequence generated in the following manner:

$$
\left\{\begin{array}{l}
x_{0} \in E, \quad \text { chosen arbitrarily, } \\
C_{1, i}=C, \\
C_{1}=\cap_{i \in \Delta} C_{1, i} \\
x_{1}=\Pi_{C_{1}} x_{0}, \\
z_{n, i}=\arg \min _{z \in E}\left\{f_{i}(z)+\frac{\|z\|^{2}}{2 r_{i}}+\frac{\left\langle z, J x_{n}\right\rangle}{2 r_{i}}\right\}, \\
y_{n, i}=J^{-1}\left(\alpha_{n, i} J z_{n, i}+\left(1-\alpha_{n, i}\right) J x_{n}\right), \quad n \geq 1, \\
C_{n+1, i}=\left\{u \in C_{n, i}: \phi\left(u, y_{n, i}\right) \leq \phi\left(u, x_{n}\right)\right\}, \\
C_{n+1}=\bigcap_{i \in \Delta} C_{n+1, i} \\
x_{n+1}=\Pi_{C_{n+1}} x_{0}, \quad \forall n \geq 1,
\end{array}\right.
$$


where $r_{i}>0, \forall i \in \Delta$, and $\left\{\alpha_{n, i}\right\}$ are sequences in $(0,1]$ such that $\lim \inf _{n \rightarrow \infty} \alpha_{n, i}>0$. Then $\left\{x_{n}\right\}$ converges strongly to $\Pi_{\cap_{i \in \Delta}\left(\partial f_{i}\right)^{-1}(0)} x_{0}$, where $\Pi_{\cap_{i \in \Delta}\left(\partial f_{i}\right)^{-1}(0)}$ stands for the generalized projection from $E$ onto $\cap_{i \in \Delta}\left(\partial f_{i}\right)^{-1}(0)$.

Proof. For each $r_{i}>0$, and $x \in E$, we see that there exists a unique $x_{r_{i}} \in D\left(\partial f_{i}\right)$ such that $J x \in J x_{r_{i}}+r_{i} \partial f_{i}\left(x_{r_{i}}\right)$, where $x_{r_{i}}=\left(J+r_{i} \partial f_{i}\right)^{-1} J x$. Notice that

$$
z_{n, i}=\arg \min _{z \in E}\left\{f_{i}(z)+\frac{\|z\|^{2}}{2 r_{i}}+\frac{\left\langle z, J x_{n}\right\rangle}{r_{i}}\right\}
$$

is equivalent to

$$
0 \in \partial\left(f_{i}+\frac{\|\cdot\|^{2}}{2 r_{i}}+\frac{J x_{n}}{r_{i}}\right) z_{n, i}=\partial f_{i}\left(z_{n, i}\right)+\frac{J z_{n, i}}{r_{i}}+\frac{J x_{n}}{r_{i}} .
$$

This shows that $z_{n, i}=\left(J+r_{i} \partial f_{i}\right)^{-1} J x_{n}$. In view of the Example 2.3 in Qin et al. [41], we find that $\left(J+r_{i} \partial f_{i}\right)^{-1} J$ is closed quasi- $\varphi$-nonexpansive with $F\left(\left(J+r_{i} \partial f_{i}\right)^{-1} J\right)=\left(\partial f_{i}\right)^{-1}(0)$.

Following the proof of Theorem 3.1, we can immediately conclude the desired conclusion.

Theorem 4.2. Let $E$ be a reflexive, strictly convex, and smooth Banach space such that both E and $E^{*}$ have Kadec-Klee property. Let $C$ be a nonempty, closed, and convex subset of E. Let $\Delta$ be an index set, and $f_{i}: C \rightarrow C$ a proper, lower semicontinuous, and convex functionals, for every $i \in \Delta$. Assume that $\cap_{i \in \Delta}\left(\partial f_{i}\right)^{-1}(0)$ is nonempty. Let $\left\{x_{n}\right\}$ be a sequence generated in the following manner:

$$
\left\{\begin{array}{l}
x_{0} \in E, \quad \text { chosen arbitrarily, } \\
C_{1, i}=C_{,} \\
C_{1}=\cap_{i \in \Delta} C_{1, i}, \\
x_{1}=\Pi_{C_{1}} x_{0} \\
z_{n, i}=\arg \min _{z \in E}\left\{f_{i}(z)+\frac{\|z\|^{2}}{2 r_{i}}+\frac{\left\langle z, J x_{n}\right\rangle}{2 r_{i}}\right\}, \\
y_{n, i}=J^{-1}\left(\alpha_{n, i} J x_{1}+\left(1-\alpha_{n, i}\right) J x_{n, i}\right), \quad n \geq 1, \\
C_{n+1, i}=\left\{u \in C_{n, i}: \phi\left(u, y_{n, i}\right) \leq \alpha_{n, i} \phi\left(u, x_{n}\right)+\left(1-\alpha_{n, i}\right) \phi\left(u, x_{n}\right)\right\}, \\
C_{n+1}=\cap_{i \in \Delta} C_{n+1, i} \\
x_{n+1}=\Pi_{C_{n+1}} x_{0}, \quad \forall n \geq 1,
\end{array}\right.
$$

where $r_{i}>0$, and $\left\{\alpha_{n, i}\right\}$ are sequences in $(0,1)$ such that $\lim _{n \rightarrow \infty} \alpha_{n, i}=0$. Then $\left\{x_{n}\right\}$ converges strongly to $\Pi_{\cap_{i \in \Delta}\left(\partial f_{i}\right)^{-1}(0)^{x}} x_{1}$, where $\Pi_{\cap_{i \in \Delta}\left(\partial f_{i}\right)^{-1}(0) \text { stands for the generalized pro- }}$ jection from $E$ onton $\cap_{i \in \Delta}\left(\partial f_{i}\right)^{-1}(0)$.

Proof. We easily find from Theorems 3.8 and 4.1 the conclusion.

Second, we consider the problem of approximating a solution of a family of variational inequalities.

Let $C$ be a nonempty, closed, and convex subset of a Banach space $E$. Let $E^{*}$ be the dual space of $E$. let $A: C \rightarrow E^{*}$ be a single valued monotone operator which is hemicontinuous; that is, continuous along each line segment in $C$ with respect to the weak* topology of $E^{*}$.

Consider the following variational inequality problem of finding a point $x \in C$ such that

$$
\langle y-x, A x\rangle \geq 0, \quad \forall y \in C
$$


In this chapter, we use $\operatorname{VI}(C, A)$ to denote the solution set of the variational inequality involving $A$. The symbol $N_{C}(x)$ stand for the normal cone for $C$ at a point $x \in C$; that is,

$$
N_{C}(x)=\left\{x^{*} \in E^{*}:\left\langle y-x, x^{*}\right\rangle \leq 0, \forall y \in C\right\} .
$$

Theorem 4.3. Let $E$ be a reflexive, strictly convex, and smooth Banach space such that both $E$ and $E^{*}$ have Kadec-Klee property. Let $C$ be a nonempty, closed, and convex subset of $E$. Let $\Delta$ be an index set, and $A_{i}: C \rightarrow E^{*}$ a single valued, monotone and hemicontinuous operator. Assume that $\cap_{i \in \Delta} \operatorname{VI}\left(C, A_{i}\right)$ is not empty. Let $\left\{x_{n}\right\}$ be a sequence generated in the following manner:

$$
\left\{\begin{array}{l}
x_{0} \in E, \quad \text { chosen arbitrarily, } \\
C_{1, i}=C, \\
C_{1}=\cap_{i \in \Delta} C_{1, i} \\
x_{1}=\Pi_{C_{1}} x_{0}, \\
z_{n, i}=V I\left(C, A_{i}+\frac{1}{r_{i}}\left(J-J x_{n}\right)\right), \\
y_{n, i}=J^{-1}\left(\alpha_{n, i} J z_{n, i}+\left(1-\alpha_{n, i}\right) J x_{n}\right), \quad n \geq 1, \\
C_{n+1, i}=\left\{u \in C_{n, i}: \phi\left(u, y_{n, i}\right) \leq \phi\left(u, x_{n}\right)\right\}, \\
C_{n+1}=\cap_{i \in \Delta} C_{n+1, i} \\
x_{n+1}=\Pi_{C_{n+1}} x_{0}, \quad \forall n \geq 1,
\end{array}\right.
$$

where $\left\{\alpha_{n, i}\right\}$ are sequences in $(0,1]$ such that $\lim _{\inf _{n \rightarrow \infty}} \alpha_{n, i}>0$. Then $\left\{x_{n}\right\}$ converges

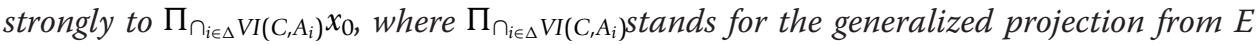
onto $\cap_{i \in \Delta} V I\left(C, A_{i}\right)$.

Proof. Define a mapping $T_{i} \subset E \times E^{*}$ by

$$
T_{i} x= \begin{cases}A_{i} x+N_{C} r, & x \in C, \\ \emptyset, & x \notin C .\end{cases}
$$

By Rockafellar [42], we know that $T_{i}$ is maximal monotone, and $T_{i}^{-1}(0)=\operatorname{VI}\left(C, A_{i}\right)$. For each $r_{i}>0$, and $x \in E$, we see that there exists a unique $x_{r_{i}} \in D\left(T_{i}\right)$ such that $J x \in J x_{r_{i}}+r_{i} T_{i}\left(x_{r_{i}}\right)$, where $x_{r_{i}}=\left(J+r_{i} T_{i}\right)^{-1} J x$. Notice that

$$
z_{n, i}=V I\left(C, A_{i}+\frac{1}{r_{i}}\left(J-J x_{n}\right)\right),
$$

which is equivalent to

$$
\left\langle y-z_{n, i}, A_{i} z_{n, i}+\frac{1}{r_{i}}\left(J z_{n, i}-J x_{n}\right)\right\rangle \geq 0, \quad \forall y \in C,
$$

that is,

$$
-A_{i} z_{n, i}+\frac{1}{r_{i}}\left(J x_{n}-J z_{n, i}\right) \in N_{C}\left(z_{n, i}\right) .
$$

This implies that $z_{n, i}=\left(J+r_{i} T_{i}\right)^{-1} J x_{n}$. In view of the Example 2.3 in Qin et al. [41], we find that $\left(J+r_{i} \partial f_{i}\right)^{-1} J$ is closed quasi- $\varphi$-nonexpansive with $F\left(\left(J+r_{i} \partial f_{i}\right)^{-1} J\right)=T_{i}^{-1}(0)$.

Following the proof of Theorem 3.1, we can immediately conclude the desired conclusion. 
Theorem 4.4. Let $E$ be a reflexive, strictly convex, and smooth Banach space such that both $E$ and $E^{*}$ have Kadec-Klee property. Let $C$ be a nonempty, closed, and convex subset of $E$. Let $\Delta$ be an index set, and $A_{i}: C \rightarrow E^{*}$ a single valued, monotone and hemicontinuous operator. Assume that $\cap_{i \in \Delta} \operatorname{VI}\left(C, A_{i}\right)$ is not empty. Let $\left\{x_{n}\right\}$ be a sequence generated in the following manner:

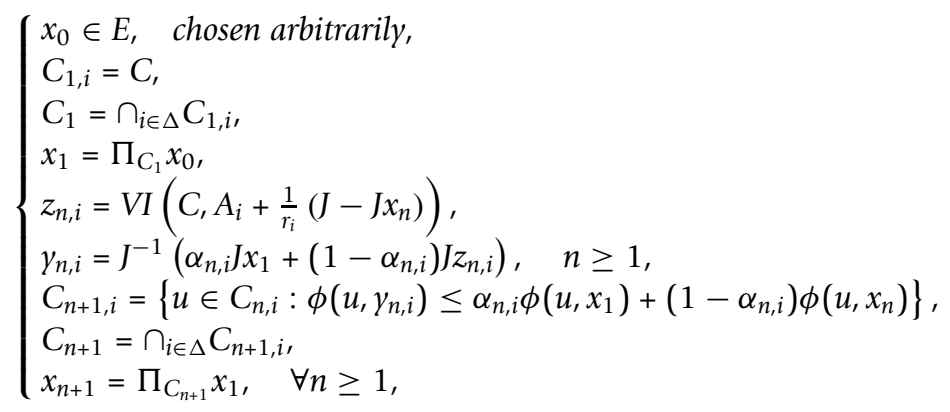

where $r_{i}>0$, and $\left\{\alpha_{n, i}\right\}$ are sequences in $(0,1)$ such that $\lim _{n \rightarrow \infty} \alpha_{n, i}=0$. Then $\left\{x_{n}\right\}$

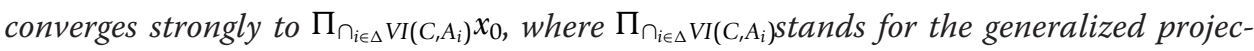
tion from $E$ onto $\cap_{i \in \Delta} \operatorname{VI}\left(C, A_{i}\right)$.

Proof. We easily find from Theorems 3.8 and 4.3 the conclusion.

\section{Acknowledgements}

The authors are grateful to the referees for their valuable comments and suggestions which improve the contents of the article.

\section{Author details}

${ }^{1}$ Department of Mathematics, Hangzhou Normal University, Hangzhou 310036, China 2Department of Mathematics, Texas A\&M University-Kingsville, Kingsville, TX 78363-8202, USA 3Department of Mathematics, Gyeongsang National University, Jinju 660-701, Republic of Korea ${ }^{4}$ Department of Mathematics and RINS, Gyeongsang National University, Jinju 660-701, Republic of Korea

\section{Authors' contributions}

All authors contribute equally and significantly in writing this paper. All authors read and approved the final manuscript.

\section{Competing interests}

The authors declare that they have no competing interests.

Received: 1 November 2011 Accepted: 13 April 2012 Published: 13 April 2012

\section{References}

1. Browder, FE: Nonexpansive nonlinear operators in a Banach space. Proc Natl Acad Sci USA. 54, 1041-1044 (1965). doi:10.1073/pnas.54.4.1041

2. Goebel, K, Kirk, WA: A fixed point theorem for asymptotically nonexpansive mappings. Proc Amer Math Soc. 35 171-174 (1972). doi:10.1090/S0002-9939-1972-0298500-3

3. Kirk, WA: A fixed point theorem for mappings which do not increase distances. Amer Math Monthly. 72, 1004-1006 (1965). doi:10.2307/2313345

4. Kirk, WA: Fixed point theorems for non-Lipschitzian mappings of as ymptotically non-expansive type. Ireal J Math. 17, 339-346 (1974)

5. $\mathrm{Xu}, \mathrm{HK}$ : Existence and convergence for fixed points of mappings of asymptotically nonexpansive type. Nonlinear Anal. 16, 1139-1146 (1991). doi:10.1016/0362-546X(91)90201-B

6. Vanderlugt, A: Optical Signal Processing. John Wiley \& Sons, New York (1992)

7. Byrne, C: A unified treatment of some iterative algorithms in signal processing and image reconstruction. Inverse Problems. 20, 103-120 (2008)

8. Genel, A, Lindenstruss, J: An example concerning fixed points. Israel J Math. 22, 81-86 (1975). doi:10.1007/BF02757276

9. Khan, MA, Yannelis, NC: Equilibrium Theory in Infinite Dimensional Spaces. Springer-Verlag, New York (1991)

10. Combettes, PL: The convex feasibility problem in image recovery. In: Hawkes, P (eds.) Advanced in Imaging and Electron Physcis, vol. 95, pp. 155-270. Academic Press, New York (1996)

11. Dautray, R, Lions, JL: Mathematical Analysis and Numerical Methods for Science and Technology. pp. 1-6. SpringerVerlag, New York (1988)

12. Fattorini, HOL: Infinite-dimensional Optimization and Control Theory. Cambridge University Press, Cambridge (1999) 
13. Güler, O: On the convergence of the proximal point algorithm for convex minimization. SIAM J Control Optim. 29, 403-409 (1991). doi:10.1137/0329022

14. Kim, JK: Strong convergence theorems by hybrid projection methods for equilibrium problems and fixed point problems of the asymptotically quasi-囚-nonexpansive mappings. Fixed Point Theory Appl 58 (2011). 2011

15. Ye, J, Huang, J: Strong convergence theorems for fixed point problems and generalized equilibrium problems of three relatively quasi-nonexpansive mappings in Banach spaces. J Math Comput Sci. 1, 1-18 (2011)

16. Matsushita, SY, Takahashi, W: A strong convergence theorem for relatively nonexpan-sive mappings in a Banach space. J Approx Theory. 134, 257-266 (2005). doi:10.1016/j.jat.2005.02.007

17. Plubtieng, S, Ungchittrakool, K: Strong convergence theorems for a common fixed point of two relatively nonexpansive mappings in a Banach space. J Approx Theory. 149, 103-115 (2007). doi:10.1016/j.jat.2007.04.014

18. Qin, X, Agarwal, RP: Shrinking projection methods for a pair of asymptotically quasi-Z-nonexpansive mappings. Numer Funct Anal Optim. 31, 1072-1089 (2010). doi:10.1080/01630563.2010.501643

19. Qin, X, Cho, YJ, Cho, SY, Kang, SM: Strong convergence theorems of common fixed points for a family of quasi- $₫-$ nonexpansive mappings. Fixed Point Theory Appl 2010 (2010). 11 Article ID 754320

20. Qin, X, Cho, SY, Kang, SM: On hybrid projection methods for asymptotically quasi-Q-nonexpansive mappings. Appl Math Comput. 215, 3874-3883 (2010). doi:10.1016/j.amc.2009.11.031

21. Qin, X, Huang, S, Wang, T: On the convergence of hybrid projection algorithms for asymptotically quasi- $₫$-nonexpansive mappings. Comput Math Appl. 61, 851-859 (2011). doi:10.1016/j.camwa.2010.12.033

22. Su, $Y$, Wang, $Z, X u, H$ : Strong convergence theorems for a common fixed point of two hemi-relatively nonexpansive mappings. Nonlinear Anal. 71, 5616-5628 (2009). doi:10.1016/j.na.2009.04.053

23. Su, Y, Qin, X: Monotone CQ iteration processes for nonexpansive semigroups and maximal monotone operators. Nonlinear Anal. 68, 3657-3664 (2008). doi:10.1016/j.na.2007.04.008

24. Zhou, H, Gao, G, Tan, B: Convergence theorems of a modified hybrid algorithm for a family of quasi-囚-asymptotically nonexpansive mappings. J Appl Math Comput. 32, 453-464 (2010). doi:10.1007/s12190-009-0263-4

25. Zhou, $\mathrm{H}$, Gao, X: A strong convergence theorem for a family of quasi- $\mathbf{Z}$-nonexpansive mappings in a Banach space. Fixed Point Theory Appl 2009 (2009). 12 Article ID 351265

26. Halpern, B: Fixed points of nonexpanding maps. Bull Amer Math Soc. 73, 957-961 (1967). doi:10.1090/S0002-9904-196711864-0

27. Cho, YJ, Qin, X, Kang, SM: Strong convergence of the modified Halpern-type iterative algorithms in Banach spaces. An Ştiinț Univ Ovidius Constanta Ser Mat. 17, 51-68 (2009)

28. Qin, X, Cho, YJ, Kang, SM, Zhou, H: Convergence of a modified Halpern-type iteration algorithm for quasi- nonexpansive mappings. Appl Math Lett. 22, 1051-1055 (2009). doi:10.1016/j.aml.2009.01.015

29. Qin, X, Su, Y: Strong convergence theorem for relatively nonexpansive mappings in a Banach space. Nonlinear Anal. 67, 1958-1965 (2007). doi:10.1016/j.na.2006.08.021

30. Martinez-Yanes, $\mathrm{C}, \mathrm{Xu}, \mathrm{HK}$ : Strong convergence of the CQ method for fixed point iteration processes. Nonlinear Anal. 64, 2400-2411 (2006). doi:10.1016/j.na.2005.08.018

31. Shzhzad, N, Zegeye, H: Strong convergence of an implicit iteration process for a finite family of genrealized asymptotically quasi-nonexpansive maps. Appl Math Comput. 189, 1058-1065 (2007). doi:10.1016/j.amc.2006.11.152

32. Agarwal, RP, Qin, X, Kang, SM: An implicit iterative algorithm with errors for two families of generalized asymptotically nonexpansive mappings. Fixed Point Theory Appl 2011 (2011). 58

33. Cioranescu, I: Geometry of Banach Spaces, Duality Mappings and Nonlinear Problems. Kluwer, Dordrecht (1990)

34. Alber, Yal: Metric and generalized projection operators in Banach spaces: properties and applications. In: Kartsatos, AG (eds.) Theory and Applications of Nonlinear Operators of Accretive and Monotone Type. pp. 15-50. Marcel Dekker, New York (1996)

35. Hudzik, H, Kowalewski, W, Lewicki, G: Approximative compactness and full rotundity in Musielak-Orlicz spaces and Lorentz-Orlicz spaces. Zeitschrift Analysis Anwendungen. 25, 163-192 (2006)

36. Takahashi, W: Nonlinear Functional Analysis. Yokohama-Publishers, Yokohama (2000)

37. Reich, S: A weak convergence theorem for the alternating method with Bregman distance. In: Kartsatos AG (ed.) Theory and Applications of Nonlinear Operatorsof Accretive and Monotone Type. Marcel Dekker, New York (1996)

38. Su, Y, Qin, X: Strong convergence of modified Ishikawa iterations for nonlinear mappings. Proc Indian Acad Sci Math Sci. 117, 97-107 (2007). doi:10.1007/s12044-007-0008-y

39. Agarwal, RP, Cho, YJ, Qin, X: Generalized projection algorithms for nonlinear operators. Numer Funct Anal Optim. 28, 1197-1215 (2007). doi:10.1080/01630560701766627

40. Qin, $\mathrm{X}, \mathrm{Su}, \mathrm{Y}, \mathrm{Wu}, \mathrm{C}, \mathrm{Liu}, \mathrm{K}$ : Strong convergence theorems for nonlinear operators in Banach spacess. Commun Appl Nonlinear Anal. 14, 35-50 (2007)

41. Qin, $X$, Cho, YJ, Kang, SM: Convergence theorems of common elements for equilibrium problems and fixed point problems in Banach spaces. J Comput Appl Math. 225, 20-30 (2009). doi:10.1016/j.cam.2008.06.011

42. Rockafellar, RT: Characterization of the subdifferentials of convex functions. Pacific J Math. 17, 497-510 (1966)

doi:10.1186/1687-1812-2012-58

Cite this article as: Qin et al:: Convergence of algorithms for fixed points of generalized asymptotically quasi- $\varphi$ -

nonexpansive mappings with applications. Fixed Point Theory and Applications 2012 2012:58. 